\title{
Mechanisms and coherences of robust design methodology: a robust design process proposal
}

\section{Göhler, Simon Moritz; Christensen, Martin Ebro; Howard, Thomas J.}

\section{Published in:}

Total Quality Management and Business Excellence

Link to article, DOI:

10.1080/14783363.2016.1180952

Publication date:

2018

Document Version

Peer reviewed version

Link back to DTU Orbit

Citation (APA):

Göhler, S. M., Christensen, M. E., \& Howard, T. J. (2018). Mechanisms and coherences of robust design methodology: a robust design process proposal. Total Quality Management and Business Excellence, 29(3-4), 239-259 . https://doi.org/10.1080/14783363.2016.1180952

\section{General rights}

Copyright and moral rights for the publications made accessible in the public portal are retained by the authors and/or other copyright owners and it is a condition of accessing publications that users recognise and abide by the legal requirements associated with these rights.

- Users may download and print one copy of any publication from the public portal for the purpose of private study or research.

- You may not further distribute the material or use it for any profit-making activity or commercial gain

- You may freely distribute the URL identifying the publication in the public portal 
This is an Accepted Manuscript of an article published by Taylor \& Francis in Total Quality Management \& Business Excellence on 09.05.2016, available online: http://www.tandfonline.com/10.1080/14783363.2016.1180952.

\section{Mechanisms and Coherences of Robust Design Methodology: a Robust Design Process Proposal}

Corresponding Author:

Simon Moritz Göhler

Department of Mechanical Engineering, Technical University of Denmark, Kgs.

Lyngby, Denmark

Produktionstorvet, Building 426, 2800 Kgs. Lyngby, Denmark

$+4552222612$

simogo@mek.dtu.dk

Martin Ebro

Valcon A/S, Denmark

$\&$

Department of Mechanical Engineering, Technical University of Denmark, Kgs.

Lyngby, Denmark

$+4530756550$

maec@mek.dtu.dk

Thomas J. Howard

Department of Mechanical Engineering, Technical University of Denmark, Kgs.

Lyngby, Denmark

$+4545254741$

thow@mek.dtu.dk 


\begin{abstract}
Although Robust Design (RD) Methods are recognized as a way of developing mechanical products with consistent and predictable performance and quality, they do not experience widespread success in industry. One reason being the lack of a coherent robust design process. In this contribution we analyze commonly used RD methods to identify their mechanisms and coherences and propose a Robust Design Process (RDP) that is connected to the actual design tasks of the design engineer. The presented RDP comprises four main activities: 1) Design and modification of the conceptual design solution, 2) Measuring and modelling the robustness of the design, 3) Processing and evaluation of the robustness data, and 4) Scaling of the design to optimize parameter and tolerance values. For each of the activities, the set of relevant Robust Design Methods is presented. The main objective of the RDP is to provide the design team with a better overview and understanding of the Robust Design toolbox and to support the application of Robust Design continuously throughout the product development by providing a sequential description of when to apply the methods and how they affect the robustness of the design.
\end{abstract}

Keywords: Robust Design, Process, Product Development, Variation, Implementation 


\section{Introduction}

The reliable and predictable functional performance of products is of crucial importance to companies that develop and produce (mechanical) products. Failures in meeting this can lead to non-satisfied customers, scrap, loss of brand value, product recalls etc. A recognized way of obtaining a high and consistent level of product quality is through the use of Robust Design Methodology (RDM). Essentially, the aim of Robust Design is to develop products with an optimized functional performance that is insensitive to variations in the noise factors as classically promoted by Taguchi (often referred to as type I RD) and to variations in the product's design parameters (type II RD) (Chen et al. 1996). Especially in early design phases type II Robust Design plays an important role to ensure flexibility in the design space later on. The IEEE (Geraci et al. 1991) defines robustness as 'the degree to which a system or component can function correctly in the presence of invalid inputs or stressful environmental conditions.' The uptake of RDM in industry is very diverse. Many example cases of applications of RD can be found in the literature (see for example (Bertini 2012; Kang et al. 2012)). Krogstie et al. also describe the successful implementation of RD in 4 well-established companies (2014). Other studies have shown that various methods that fall into the suite of RD are regularly applied in industry (Araujo et al. 1996; Fujita and Matsuo 2005). Especially tolerance design is a very common method to ensure functional robustness (Chase and Parkinson 1991). However, surveys conducted in the UK, Sweden and USA suggest that both in terms of knowledge and usage the concept of Robust Design is still not experiencing widespread success (Araujo et al. 1996; Gremyr, Arvidsson, and Johansson 2003; Thornton, Donnelly, and Ertan 2000). The lack of a Robust Design Process - a coherent approach structuring and arranging all individual methods in the RDM landscape - has been reported to be one reason (Krogstie, Ebro, and Howard 
2014). Seen from the design engineer's point-of-view, an extensive toolbox is provided by the literature, but it is relatively unclear how the methods are connected, in which order they should be used and how to transfer the mind-set of Robust Design into an ordered set of activities. However, the current research streams do not seem to address this issue.

This contribution has two objectives. Firstly, to clarify the mechanisms of Robust Design: i.e. what are the mechanisms of the available Robust Design methods? Secondly, to find coherences between the methods, and identify how these relate to the activities of the design engineers and propose a coherent Robust Design Process. The RDP shall be a "next step" guide on where the single tools can be positioned. It should fulfil the following requirements:

Req 1: The process should house all RD methods

Req 2: The process should provide a sequence of use of all RD methods Req 3: The process should link to the activities of the design engineers

Robust Design is a method and tool driven field. To reach the objectives, we therefore analyze methods commonly associated with RD to derive how they work. We then describe their coherences and propose a Robust Design process based on general design activities, which supports the design engineer's pursuit of a robust design throughout the product development process (PDP). The application of the RDP in specific contexts is out of scope for this study. Figure 1 summarizes the methodology. 


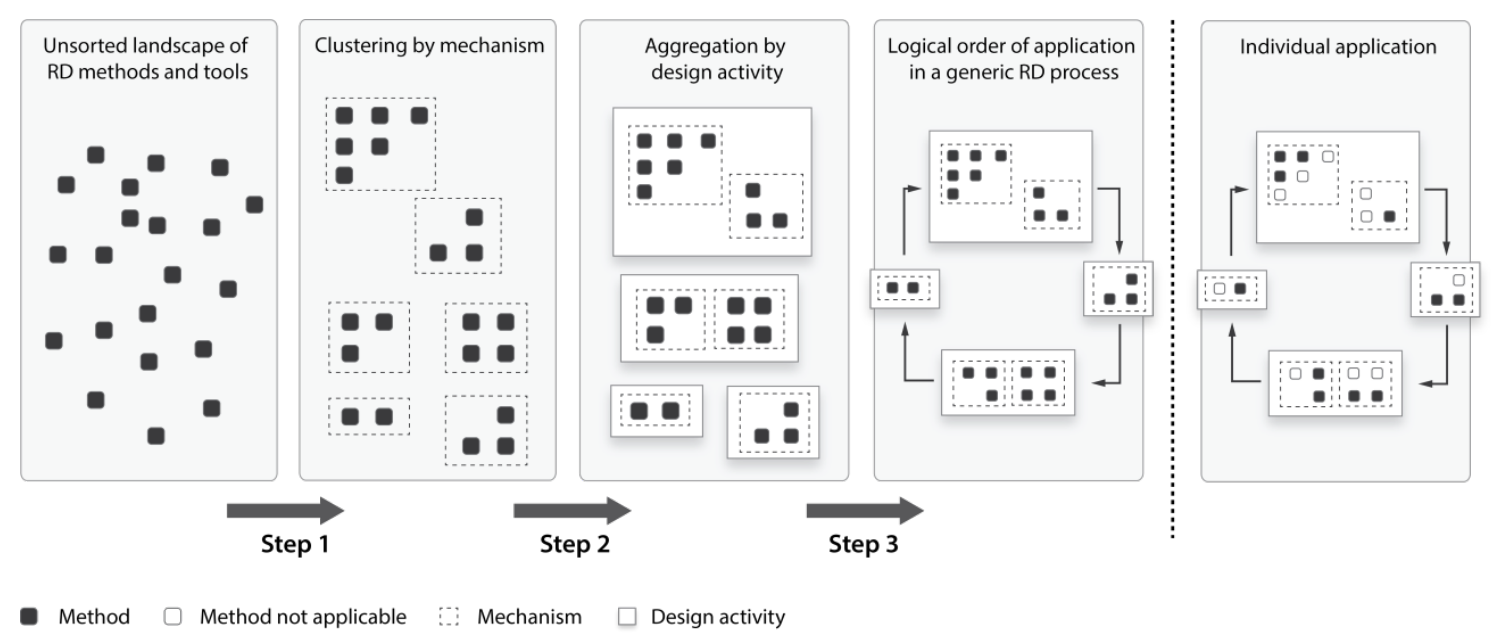

Figure 1: Deriving the Robust Design Process

It is the intention that the RDP should be applicable in all design stages and that it can be used not only as an analysis toolbox, but rather act as a complete framework containing synthesis tools as well. The underlying assumption for this study is that the Robust Design Methodology can be represented by its methods and tools. Due to the authors' background in mechanical engineering the focus is mainly on the Robust Design of mechanical products.

The outline of the article is as follows. In section 2 we present a literature study on the most recent research in the field of Robust Design to get an idea of current research streams in that area and if the identified issues regarding the application of RD in industry are being addressed. In the proceeding chapter we analyze the methods and tools commonly associated with RD and elaborate on the applicability of available processes and frameworks followed by our proposal of the RDP. The article closes with a discussion and a conclusion.

\section{Current Research in Robust Design}

Robust Design has been subject to numerous research projects and has therefore also led 
to many publications in the past decades. To judge current trends within the field, recent publications since 2010 have been reviewed. The Google Scholar search engine has been used to extract 80 relevant papers. The selection of relevant papers was done by screening of the titles and abstracts and solely based on the authors' opinion about the papers' relevance to RD. The selection is comprehensive but selective.

\subsection{Robust Design Methods}

Robust Design has its origins in Taguchi's ideas of quality loss occurring with any deviation from the target performance and the so called Taguchi Method consisting of System, Parameter and Tolerance Design (Taguchi, Chowdhury, and Wu 2005).

Recently, Ebro et al. (2012) promoted the use of Kinematic Design and Design Clarity to ensure the right number and way of constraining parts in an assembly for an improved System Design.

However, the largest share of recent publications deals with Robust Design Optimization (RDO). RDO is directly related to Taguchi's Parameter Design where experimental data and the Signal-to-Noise-Ratio are used to measure and optimize the robustness of single functions. Eifler et al. (2011) and Hutcheson et al. (2012) present further sensitivity measures and indices to quantify robustness. Yadav et al. and Yang et al. $(2010 ; 2014)$ utilize the total quality loss as cost function in the optimization to account for multiple objectives. Other scholars, like Saha and Ray (2011), focused on the improvement of the efficiency and performance of the optimization algorithms themselves. Another stream within RDO is Reliability Based Robust Design Optimization (RBRDO) and probabilistic RD taking the uncertainties and the probability of the occurrence of variation into account to optimize the robustness and reliability of products as opposed to the deterministic original approach by Taguchi. Many contributions on novel and improved algorithms for RBRDO can be found in the 
recent literature (see for example Steenackers et al. (2011), Tang et al. (2012), Shahraki et al. (2014)). Lijuan et al. (2011) propose a method to integrate Robust Design, Axiomatic Design and reliability-based design to improve the efficiency of the optimization. Various case studies on RDO were conducted. Among those are for example the robust optimization of a low pressure turbine of a jet engine and a suspension system (Bertini 2012; Kang et al. 2012).

The simulation and prediction of geometric variations for assemblies is another research field within RD that is related to Taguchi's Tolerance Design. Schleich et al. (2012) use skin models to incorporate manufacturing data to increase the detail and accuracy of geometric variation simulation. Other studies seek to extent geometric variation simulations by for example including the influence of welding on the final assembly (Pahkamaa et al. 2012) or by regarding deformable, slender parts like cables and hoses (Hermansson, Carlson, and Bjo 2013).

\subsection{Robust Design Frameworks}

Apart from the mentioned research on RD methods some recent publications deal with the general organization and framing of RDM to increase the understanding and the efficiency of the application. Howard et al. (2014) proposed a framework to structure RD efforts introducing a mapping of the influences of variation from the production all the way to the customer perception of the final product. Göhler and Howard (2014) introduced a way to classify tools and methods associated with RD to clarify their purposes for a more efficient application.

\subsection{Application of Robust Design in Industry}

Other recent studies looked at the use of RD in industry. Gremyr and Hasenkamp (2011) investigated the application of RD (especially Design of 
Experiments) in a medium-sized Swedish company. They found that RDM tools are applied regularly but that 'the principle of insensitivity to noise factors has not fully permeated the general way of thinking' and therefore hindered the optimal use of the tools. Mashhadi et al. $(2012 ; 2015)$ studied the introduction of Robust Design at Volvo. The first attempt of 'tool-pushing' by management did not find acceptance and failed. Based on the experiences, a second initiative was developed founded on 'practicepulling through local learning processes in the organization' which turned out to be successful.

The literature review on recent publications associated with RD suggests that current research activities mostly focus on the improvement and extension of Robust Design Methods - especially RDO in various forms. Deterministic and probabilistic optimizations taking the reliability perspective into consideration contribute with a large proportion of the latest publications. Case studies on robust optimization constitute another large share of the publications. Generally speaking, the current research streams within RD are rather method dominant and do not address the issue of implementation and application of RD in industry. Only five out of the 80 reviewed papers deal with framing RDM or the application of RDM in industry. There is still a lack of a coherent and structured RD process putting available and established as well as new methods into context and thereby easing the application in industry.

\section{Analysis of Robust Design Methods}

In this section we analyze common RD methods and tools to derive their mechanisms and working principles. The goal is to establish a common base to evaluate existing frameworks and processes in the area of Robust Design against the requirements of a coherent Robust Design Process as defined in the introduction. 


\subsection{Selection of tools}

There are numerous tools and methods being used in product development to support the design engineers in their work covering various fields within the Design for $\mathrm{X}$ (DfX) spectrum. For this investigation only the tools and methods commonly associated with Robust Design were taken into account. However, some of them are not exclusively Robust Design tools but are also used in other contexts and fields not focusing on reducing sensitivities and functional variation. The tools were selected from four sources:

(1) Robust Design Methods in industry

To reflect the actual application of Robust Design Methodology in industry four large companies in product development and engineering consultancy were asked to share their Robust Design tool boxes. The companies are not representative but were chosen for their rigorous implementation and application of RDM. The aim of this contribution is neither to compare different tool boxes nor their frequencies of use. This short survey shall rather give an idea about which methods are actually being used and ensure their capturing in the derivation of the RD process.

(2) RDM reviews and surveys in literature

To consider a wide range of different methods and tools, the list from 1) was augmented by additional tools extracted from the Robust Design literature. Existing reviews and classifications of RD methods were used as sources (Hasenkamp, Arvidsson, and Gremyr 2009; Matthiassen 1997; Eifler, Ebro, and Howard 2013). Furthermore, methods mentioned in surveys about the industrial use of Robust Design in various regions of the world were also included (Gremyr, Arvidsson, and Johansson 2003; 
Araujo et al. 1996; Thornton, Donnelly, and Ertan 2000).

(3) Robust Design Special Interest Group (SIG) workshops and surveys

The Robust Design SIG ran workshops and surveys on the ICED13, Design14 and ISoRD14 conferences asking participants from academia and industry to name and place RD methods and tools they actively apply.

\section{(4) Authors' experience}

The authors have worked as Robust Design consultants and as development engineer within an aerospace company, totaling 15+ years of experience working with applied Robust Design and therefore have hands-on experience with many of the Robust Design Methods.

\subsection{Delimitation}

Any given body of methods will be surrounded by somewhat related methods.

Therefore a delimitation of the field is necessary. We follow our working definition of RD methods as stated in the introduction. Some methods that are often mentioned in the Robust Design literature do not fall into this category and are therefore excluded from the process model. These include:

\subsubsection{Methods for identifying customer and functional requirements}

Although the starting point for an analysis of the robustness of a design would typically be the identification of the functional requirements, this is regarded as out-of-scope in this context, as Requirements Management is regarded as a separate topic typically carried out by other people than the design engineers, which are the target audience for this publication. Therefore, methods such as Quality Function Deployment (QFD), 
Voice-of-the-customer (VOC), etc. are not included in the process model.

\subsubsection{Methods relating to reliability and risk management}

In a design project, there are numerous risks that can affect the performance of the product and the project. Disturbances in the supply chain, misuse of the product, components being mixed up or forgotten during assembly, etc. All entail a risk, but can be said to be out of the hands of the design engineer, i.e. these risks have to be dealt with by other people and by other means than changing the features of the design. Furthermore, although FMEA and FTA are often mentioned in literature as belonging to the suite of Robust Design Methods, it is the opinion of this research that they do not belong there.

Table 1 lists commonly used Robust Design methods and tools in alphabetical order including short descriptions. The list is not complete but comprehensive from the authors' point of view.

\begin{tabular}{|c|c|c|c|c|c|}
\hline Methods and Tools & Short Description & 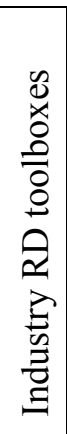 & 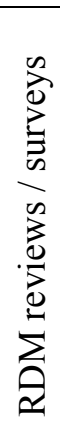 & 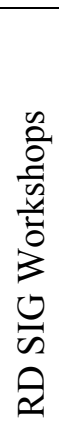 & 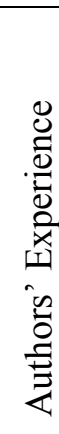 \\
\hline $\begin{array}{l}\text { Analytical Transfer } \\
\text { Function Modelling }\end{array}$ & $\begin{array}{l}\text { Usage of analytical mathematical expressions to } \\
\text { (simplify and) model functional responses. }\end{array}$ & & $\checkmark$ & & $\checkmark$ \\
\hline $\begin{array}{l}\text { 2. Axiomatic Design } \\
\text { Axiom } 1\end{array}$ & $\begin{array}{l}\text { Striving for the independence of functions } \\
\text { (decoupling, uncoupling) can yield robustness }\end{array}$ & & $\checkmark$ & $\checkmark$ & $\checkmark$ \\
\hline $\begin{array}{l}\text { 3. Axiomatic Design } \\
\text { Axiom } 2\end{array}$ & $\begin{array}{l}\text { Maximization of the probability of fulfilling the } \\
\text { functional requirements by reducing the number of } \\
\text { influencing factors and designing to process } \\
\text { capabilities }\end{array}$ & & $\checkmark$ & $\checkmark$ & \\
\hline 4. Design Clarity & $\begin{array}{l}\text { Design for unambiguous interfaces and force } \\
\text { transmission }\end{array}$ & $\checkmark$ & $\checkmark$ & $\checkmark$ & $\checkmark$ \\
\hline
\end{tabular}




\begin{tabular}{|c|c|c|c|c|c|}
\hline 5. Design Matrix & $\begin{array}{l}\text { Linear mapping between functional output and } \\
\text { design parameters in matrix form. }\end{array}$ & & & & $\checkmark$ \\
\hline $\begin{array}{ll}\text { 6. } & \text { Design of } \\
\text { Experiments (DOE) }\end{array}$ & $\begin{array}{l}\text { Statistically designed experiments to maximize } \\
\text { information and minimize number of required } \\
\text { experiments. }\end{array}$ & $\checkmark$ & $\checkmark$ & $\checkmark$ & $\checkmark$ \\
\hline $\begin{array}{l}\text { 7. Design Structure } \\
\text { Matrix }\end{array}$ & $\begin{array}{l}\text { Matrix representation of structures and correlations in } \\
\text { complex systems. }\end{array}$ & & & & $\checkmark$ \\
\hline $\begin{array}{ll}\text { 8. } & \text { Error Transmission } \\
& \text { Formula }\end{array}$ & $\begin{array}{l}\text { Calculation of the variance of a function utilizing } \\
\text { sensitivities and variances of the influencing factors. }\end{array}$ & & $\checkmark$ & & \\
\hline $\begin{array}{l}\text { 9. Ishikawa / Fishbone } \\
\text { Diagram }\end{array}$ & $\begin{array}{l}\text { Systematical decomposition of influencing factors to } \\
\text { a function in a fishbone-like graphical representation. }\end{array}$ & $\checkmark$ & $\checkmark$ & & $\checkmark$ \\
\hline 10. Kinematic Design & Design for ideally constrained mechanisms & $\checkmark$ & $\checkmark$ & $\checkmark$ & $\checkmark$ \\
\hline 11. Locat & $\begin{array}{l}\text { Design for ideally constraining all } 6 \text { degrees of } \\
\text { freedom in assemblies }\end{array}$ & $\checkmark$ & $\checkmark$ & $\checkmark$ & \\
\hline 12. Monte-Carlo-Analysis & $\begin{array}{l}\text { Statistical evaluation of repeated model simulations } \\
\text { based on random sampling of input parameters } \\
\text { following predefined probability distributions. }\end{array}$ & $\checkmark$ & $\checkmark$ & & $\checkmark$ \\
\hline $\begin{array}{l}\text { 13. Optimization of } \\
\text { transfer function or } \\
\text { S/N-Ratio }\end{array}$ & $\begin{array}{l}\text { Derivation and optimization of cost functions relating } \\
\text { to functional performance and variance. }\end{array}$ & $\checkmark$ & $\checkmark$ & $\checkmark$ & \\
\hline 14. P-di & $\begin{array}{l}\text { Graphical representation of a function or process } \\
\text { distinguishing between 1) signal/input factors, 2) } \\
\text { control factors, 3) noise factors, 4) output }\end{array}$ & $\checkmark$ & $\checkmark$ & & $\checkmark$ \\
\hline 15. Pareto Analysis & $\begin{array}{l}\text { Derivation and ranking of most influencing factors } \\
\text { towards a functional output. }\end{array}$ & & $\checkmark$ & & $\checkmark$ \\
\hline $\begin{array}{l}\text { 16. Response Surface } \\
\text { Methodology and } \\
\text { other data fitting } \\
\text { methods }\end{array}$ & $\begin{array}{l}\begin{array}{l}\text { Statistical fitting of a surrogate } \\
\text { experimental data. }\end{array}\end{array}$ & $\checkmark$ & $\checkmark$ & & \\
\hline $\begin{array}{l}\text { 17. Safety factors wrt. } \\
\text { structural properties } \\
\text { and process capability } \\
\text { data }\end{array}$ & $\begin{array}{l}\text { Include safety factors to account for variations and } \\
\text { uncertainties. }\end{array}$ & $\checkmark$ & $\checkmark$ & $\checkmark$ & $\checkmark$ \\
\hline $\begin{array}{l}\text { 18. Selection of robust } \\
\text { working principle and } \\
\text { conceptual design } \\
\text { solution }\end{array}$ & $\begin{array}{l}\text { Inherently more robust working principles shall be } \\
\text { exploited }\end{array}$ & $\checkmark$ & $\checkmark$ & $\checkmark$ & $\checkmark$ \\
\hline 19. Sensitivity Analysis & $\begin{array}{l}\text { Assessment of sensitivities of functions to variation } \\
\text { in single or multiple parameters }\end{array}$ & $\checkmark$ & & $\checkmark$ & $\checkmark$ \\
\hline $\begin{array}{l}\text { 20. Separation/ } \\
\text { Integration }\end{array}$ & $\begin{array}{l}\text { Separation/Integration of functions to reduce } \\
\text { functional variance }\end{array}$ & $\checkmark$ & $\checkmark$ & & $\checkmark$ \\
\hline 21. Tolerance Chains & $\begin{array}{l}\text { Derivation of the influence of tolerances on resulting } \\
\text { gaps or overlaps in assemblies. Strive for short }\end{array}$ & $\checkmark$ & $\checkmark$ & $\checkmark$ & $\checkmark$ \\
\hline
\end{tabular}




\begin{tabular}{|c|c|c|c|c|}
\hline & $\begin{array}{l}\text { tolerance chains to reduce variation of the gap or } \\
\text { overlap. }\end{array}$ & & & \\
\hline $\begin{array}{l}\text { 22. Tolerance } \\
\text { Management }\end{array}$ & $\begin{array}{l}\text { Optimization of tolerance allocations to reduce } \\
\text { functional variation and cost. }\end{array}$ & $\checkmark$ & $\checkmark$ & $\checkmark$ \\
\hline $\begin{array}{l}\text { 23. Variation Mode and } \\
\text { Effects Analysis }\end{array}$ & $\begin{array}{l}\text { Subjective quantification of the occurrence and } \\
\text { impact of variation on the functional performance. }\end{array}$ & & $\checkmark$ & $\checkmark$ \\
\hline
\end{tabular}

Table 1: List of commonly used methods in RD

\subsection{Mechanisms and working Principles of RD Methods and Tools}

As shown in Figure 1 step 1 it is the goal to increase the understanding of the inherent mechanisms and working principles of the RD methods and tools to then in the next step be able to assign them to specific activities of the engineer. A way to describe how Robust Design methods work is through the model of the Transfer Function (TF). The $\mathrm{TF}$ is the mathematical description of the functional performance dependent on the influencing parameters (usually in the form $f=f\left(x_{1}, \ldots, x_{n}\right)$ ). Although methods have different names and may have minor differences in the way they are described or applied, they can ultimately be categorized based on how they affect the Transfer Function. Using the Transfer Function as a reference to analyze each of the Robust Design Methods listed in Table 1, eight different independent mechanisms related to Robust Design have been identified. In the following, the identified mechanisms of the RDM, i.e. the interactions of the methods with the Transfer Function and therefore the robustness of the design, are described. The results are summarized in Table 3.

\section{(1) Robust concept design}

Following design guidelines and best practices can influence the robustness already in the conceptual stage. The selection of the working principle and the conceptual system design solution can have a major effect on the robustness of the concept and subsequently the final design. Taguchi et al. (2005) as well as Andersson (1996) stress 
the importance of system design, especially conceptual design. Generally, different working principles yield very different system and function responses, i.e. transfer functions, and can therefore differ greatly in terms of robustness against variation.

\section{(2) Reduction of couplings between functions}

In the case of a multi-function design it is likely that different functions share the same influencing parameters - so-called Design Parameters (DPs). The functions are therefore said to be coupled. However, the functional response and also the sensitivity towards the DP can be very different or even contradicting. Also, the target values and the design range differ in most cases which makes trade-offs necessary compromising the overall performance. The Independence Axiom (Axiom 1) of Suh's Axiomatic Design (Suh 2001) addresses the coupling of functions and its implications. He proposes to unor decouple the functions from each other to obtain independent functions that can be adjusted by a set of DPs that do not interfere with other functions. Matthiassen (1997) describes the differentiation and separation of functions as means to avoid compromising the performance due to conflicting or contradicting demands (functional requirements).

\section{(3) Reduction of number of influencing factors}

A product's functions are defined by the correlation of design parameters (DP) and noise factors (NF) to the function response or output. The model of the Transfer Function captures all of these influencing factors. In the light of robustness, i.e. variability, of the functional response, all the influencing factors contribute with their variation. Assuming the independence of the DPs and NFs and a normal distribution, the Taylor Series expansion gives 


$$
\sigma_{f}^{2}=\sum_{i=1}^{n}\left(\frac{\partial f}{\partial x_{i}}\right)^{2} \sigma_{i}^{2}
$$

$\sigma_{\mathrm{i}}$ and $\sigma_{\mathrm{f}}$ are the standard deviations of the $\mathrm{i}^{\text {th }}$ influencing factor and the functional performance respectively. As a result, the total possible variance of the resulting functional output increases with the number of influencing factors (or remains the same at best). Suh (2001) describes this with the Information Axiom (Axiom 2 in Axiomatic Design). The probability of fulfilling the functional requirement is inversely proportional to the information content. In other words, the lower the information content the higher the probability of achieving the desired functional response. Many researchers including Pahl, Beitz and Grote (2007), Matthiassen (1997) and Mørup (1993) elaborated over the use of design guidelines and principles to ultimately lower the number of influencing factors for an increase in predictability and robustness. Examples are to avoid long tolerance chains, utilize self-adjustment, unambiguous loading and many more (22 in total). The tools of location schemes, design clarity and kinematic design facilitate the principles of ideally constrained interfaces and mechanisms and, hence, reduce the number of influencing factors, to obtain unambiguous force flows (Söderberg, Lindkvist, and Carlson 2006; Ebro, Howard, and Rasmussen 2012).

\section{(4) Design with robustness margins}

A common and widely used approach especially in the first iteration loop of product development is to build in margins. This might be costly in the way that the design is over-dimensioned, however, margins do not only cover uncertainty in the calculations and assumptions but also uncertainties in production and use, hence robustness. Typical and established margins are structural safety factors, where e.g. the maximum 
allowable stress or strain is a factor smaller than the actual material properties in order to allow for variation.

\section{(5) Measuring of system response}

The measuring of robustness represents a large fraction of the Robust Design Methodology. The central point is the measurement of the system or function response in the design space and how it changes due to a change in one or more of the design parameters and noise factors. Simple one-factor-at-the-time screening procedures become costly very quickly for an increased number of experiments or simulations due to changing parameters and levels and don't capture interaction effects. Structured planning of experiments and simulations helps exploring the design space in an effective and efficient manner. Design of Experiments (DoE) has its roots in the 1920s starting with work from Fisher and reaches up to today (Antony 2003). Taguchi operationalized orthogonal arrays which were further developed by Welch, Yu, Kang, and Sacks (1990). The data gained from the experiments (testing) and simulations build the backbone for empirically derived transfer functions.

\section{(6) Modeling of system response}

The prediction and optimization of the system or functional response requires the formulation of a model, i.e. a transfer function. The TF can be derived from measurement data or simulation results by fitting (regression modeling) a polynomial or other mathematical functions to the data. The Response Surface Methodology by Box and Wilson is one of the well-established ways to derive the transfer function from big datasets (Box and Wilson 1951). In some cases the transfer functions can also be derived analytically. In Axiomatic Design by Suh, Design Matrices are derived for the transfer functions and the mapping between the functional and physical domain (Suh 
2001). However, the matrix form bears the disadvantage of linearity and is hence not suitable for most real design problems. An alternative, more simple and qualitative way of deriving a transfer function, is by using Variation Modes and Effects Analysis (VMEA), which is essentially an estimation of the system response based on experience from previous designs.

\section{(7) Processing and evaluation of system response}

Several methods and tools in the RDM can be applied to evaluate the robustness based on the mathematical formulation of the system response. The two types of outputs are metrics and visualizations, where the visualization can be quantitative based on the metrics or qualitative.

\section{Metrics}

Sensitivity values and ratios for single or multiple design parameters or noise factors can be derived from the gradient of the Transfer Function or by utilizing Sensitivity Analyses. Estimated yield rates and variances of the functional outputs can be calculated utilizing Monte Carlo analysis or the Error Transmission Formula. The Signal-to-Noise Ratio expresses the relative magnitude of the variation compared to the intended performance.

\section{Visualizations}

The plotting of the transfer function with respect to one or multiple design parameters or noise factors is one way of visualization. Qualitative representations like in Fishbone and P-Diagrams where the influencing factors, but not their contribution and sensitivities are captured are very common in the RDM. Also matrix-based representations like Design Structure Matrices (DSMs) can help visualize the relations 
between functions and design parameters or the coupling of functions. Pareto-Analyses are often used to visualize the sensitivity of the individual design parameters quantitatively.

\section{(8) Scaling of design parameters}

The function response to the Design Parameters is often non-linear. That suggests that there are settings of the Design Parameters that minimize the variance of the functional response. Most designs cannot be idealized to an uncoupled or decoupled design with only one main design parameter for each function. Realistic design problems tend to be more complex integrating a lot of functionality. To find a robust design despite of couplings, restrictions and constraints it is desired to scale all Design Parameters in a way that the nominal functional response is met but also the variance is minimized. The Transfer Function itself (for example in the form of a Response Surface model) and the Signal-to-Noise ratio (SNR) as used by Taguchi can be utilized to optimize the design parameters for target and variance of a function's output. In the Taguchi Method this stage is called Parameter Design (Taguchi, Chowdhury, and Wu 2005). Other researchers have developed other cost functions to optimize the design's robustness. Tolerance management is a more and more integral part of the RD optimization.

\section{Robust Design Processes and Frameworks}

In the literature, different descriptions of method classifications, frameworks and processes related to Robust Design can be found. Robust Design was first introduced by Taguchi in the 1950s. The so-called Taguchi method was the first framework incorporating the ideas and mind-sets of Robust Design and is still used in developing companies. Taguchi distinguished between 3 main phases of Robust Design: 1) the System Design which corresponds to concept and embodiment of a design solution 
addressing the functional requirements of the product, 2) the Parameter Design phase in which the design is optimized for robustness - designed experiments are used to gain understanding about the system behavior and the sensitivity of design parameters and noise factors, followed by the actual optimization of the signal-to-noise $(\mathrm{S} / \mathrm{N})$ ratio - and 3) the setting of tolerances optimizing the design with respect to manufacturing costs (G. Yang 2007). The Taguchi approach focuses on type I RD to optimize the robustness against noise factors utilizing systematic experimentation following orthogonal arrays in the Parameter Design phase. System Design and Tolerance Design play a less important role since Taguchi sees them as 'specialist's territory' and last 'countermeasure' to ensure a robust performance respectively (Taguchi, Chowdhury, and $\mathrm{Wu} 2005$ ).

In recent years, Design for Six Sigma (DfSS) has become relatively successful in industry (Goh 2002). The mindset of DfSS is similar to the approach found in the Six Sigma paradigm of continuous improvement. But where Six Sigma is aimed at improving an existing process, the objective of DfSS is to design a reliable product from the ground-up (Creveling, Slutsky, and Antis 2002). In DfSS, the approach is typically called IDOV (or something similar) comprising a series of steps each containing suggested methods. The IDOV steps are: 1) Identify customer and product requirements using e.g. Quality Function Deployment (QFD) and Voice-of-thecustomer (VOC), 2) Design conceptual solutions and identify risks using e.g. Failure Modes and Effects Analysis (FMEA), 3) Optimize the design using process capability information, Robust Design methods, Monte Carlo simulations and tolerance management and finally 4) Validate the design by testing and reviewing, using e.g. accelerated lifetime tests (HALT), reliability engineering and FMEA. DfSS is meant to be a comprehensive 'concept aiming at Six Sigma performance by improved design activity' (Hasenkamp 2010) to give a high level guidance for quality and reliability 
activities of a developing company. However, Robust Design is only seen as a subset of this as part of the Optimize step and although it is not described in great detail it is noticeable that it is seen as a late-stage analysis and optimization of the design.

Other frameworks associated with RD deal with variation management. Variation Risk Management (VRM) proposed by Thornton is one of them (2004). VRM is a framework to structure efforts to reduce risks caused by variation. It includes 22 industry practices that are applied in three general stages. 1) The Risk identification stage where a system of so-called variation risk factors is created. This includes the identification of key characteristics (KCs) in a risk flow down manner comprising four levels: Product KCs, Sub System KCs, Part KCs and Process KCs. 2) The Risk Assessment with two general approaches - one being the prediction of the final quality by summing up all individual process variations. The second one utilizes a top-downapproach allocating allowable variation to the single features in the form of tolerances. In that approach the assigned tolerances are compared to the predicted process capability (Cpk) values to predict the final quality. The risk assessment builds upon the variation modeling, the feedback of production capabilities and the estimation of capability uncertainty. And 3) the Risk Mitigation through design changes and process improvements. This includes the practices of cost/benefit trade-offs, Robust Design and Manufacturing Quality plans. For Robust Design Thornton refers to the Taguchi method. The VRM framework addresses the entire variation problem including ingoing variation, i.e. the capability of the production processes as well as the sensitivity of the design to variation. In VRM, Robust Design is seen as part of the risk mitigation activities. VRM focuses more on the production side and on allocating parameter variation and predicting functional variation, than supporting the design engineer in the 
effort of designing an inherently robust design by changing the geometry and features of the design.

Hasenkamp et al. (2009) made an attempt to frame the Robust Design Methodology answering the questions: Why should RD be used? What should be done and how should it be done? They distinguish between 1) principles, 2) practices, and 3) tools of RD. As principles they mention 'Awareness of Variation', 'Focus on the Customer' and 'Continuous Applicability' explaining the overall mind-set of a continuous focus on variation. Practices give a high-level, fundamental input on how robustness can be achieved and cover design rules, insensitivity to noise factors and robust optimization. The actual RD activities and methods are summarized in tools including mainly analysis tools like VMEA, P-Diagram, TF and DoE in an unstructured manner. Fazl Mashhadi et al. (2015) extended the framework based on their experiences in industry. The main aim of this framework is to convey the goal and mindset of Robust Design facilitated by certain practices and tools to assist the implementation, acceptance and application of RD in industry.

Göhler and Howard (2014) provide a more detailed classification of Robust Design Methods, categorizing the methods based on the objective or purpose of applying them. The methods are classified as supporting one or more of the four categories: 1) Robust Design Principles, 2) Robust Design Evaluation, 3) Robustness Optimization and 4) Robustness Visualization. These categories are not stitched together to a coherent process, but shall rather give practitioners a guidance and understanding of what certain methods in RD are used for and what they can deliver.

The Axiomatic Design framework by Suh introduces 2 axioms namely the Independence and the Information Axiom. The main idea is to reduce the coupling of functions in a design (independence of functions) and to strive for minimized 
information content. The robustness of a design is measured with the probability of fulfilling all functional requirements simultaneously. This probability is inversely proportional to the information content (Suh 2001). In practice this framework can be seen as design guideline which provides heuristics for a good and robust design.

Howard et al. (2014) propose the Variation Management Framework (VMF) for Robust Design. It maps the variation of production variables through transfer and quality loss functions to the customer satisfaction of the product on the market. The VMF is a simplification of the mapping of variations through the production, design and customer domain. It has its strengths in the simple and easy description and visualization of the need and influence of Robust Design.

\subsection{Gaps in existing frameworks}

The presented frameworks pursue different objectives in framing and prescribing Robust Design. Their main shortcomings are discussed below and summarized in Table 2:

- Lack of low-level guidance and connection to design activities of design engineers.

From the review we found that the majority of frameworks and processes address managerial and organizational or theoretical and academic aspects of RD. The frameworks provide a high level overview of how RD fits into the overall development process. But seen from the design engineer's or project manager's point-of-view, the frameworks do not provide detailed guidance on the specific activities of Robust Design or are very focused on single methods (like Taguchi Method and Axiomatic Design). In DfSS, VRM and VMF, Robust Design is merely a subset of the overall framework and not described in great detail. The lack of understanding of applicability of the methods 
and their coherences is not addressed. Further, there is no prescribed sequence for the application of RDM.

- $\quad$ Synthesis tools missing.

Another finding is that most of the frameworks do not address the whole landscape and mechanisms of RD as identified in Section 3. The synthesis part is often neglected and Robust Design is mainly seen as an analysis and optimization tool, i.e. the frameworks provide methods that can be used to analyze the current level of robustness and optimize it within the constraints of the given concept, but they do not provide any guidance for the design engineer at the point-of-design, i.e. during the actual sketching and modelling. As a consequence, the final design may simply end up as being a suboptimized version of the initial concept, rather than an inherently robust concept, based on guidelines and principles for obtaining robust concepts. This is especially unfortunate, since the actual measuring and modelling of the robustness can be challenging and costly.

- Unordered and unsorted list of Robust Design Methods.

The frameworks describe an array of relevant methods, but do not go into details about which order to apply the tools in and what the objective of the individual tool is. A coherent RD process is lacking. The foci and objectives of methods are often missing leaving the practitioners with a potentially overwhelming toolbox. 


\begin{tabular}{|c|c|c|c|c|c|c|c|c|c|c|c|c|c|}
\hline & \multicolumn{8}{|c|}{ Categories of RD methods and tools } & \multicolumn{2}{|c|}{ Target Group } & & & \\
\hline Framework & 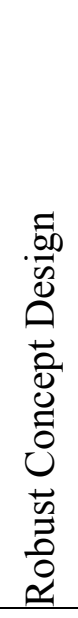 & 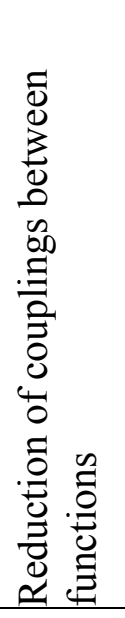 & 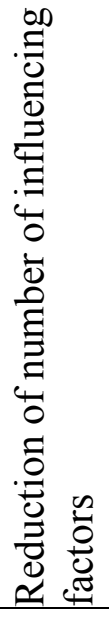 & 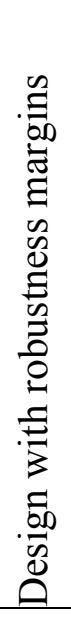 & 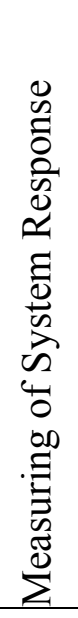 & 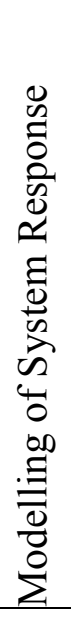 & 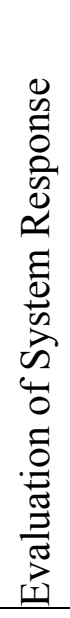 & 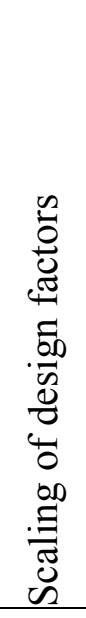 & 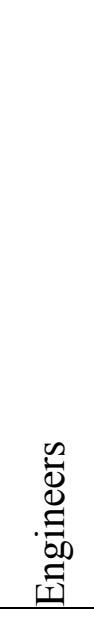 & 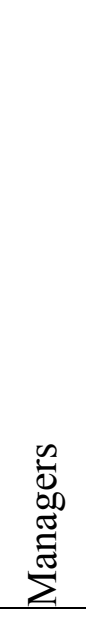 & 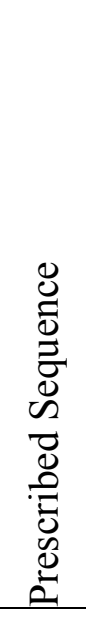 & 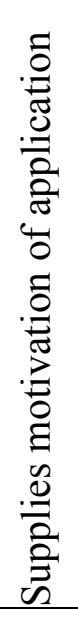 & 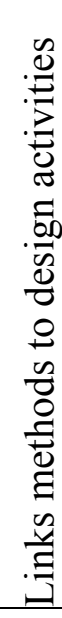 \\
\hline Taguchi & $\checkmark$ & & & & $\checkmark$ & $\checkmark$ & $\checkmark$ & $\checkmark$ & $\checkmark$ & & $\checkmark$ & $\checkmark$ & $\checkmark$ \\
\hline DfSS & \multicolumn{8}{|c|}{$\mathrm{RD}$ is a subset and not specified further } & & $\checkmark$ & $\checkmark$ & & \\
\hline VRM & \multicolumn{8}{|c|}{$\mathrm{RD}$ is a subset and not specified further } & & $\checkmark$ & $\checkmark$ & & \\
\hline Hasenkamp & $\checkmark$ & $\checkmark$ & $\checkmark$ & $\checkmark$ & $\checkmark$ & $\checkmark$ & $\checkmark$ & $\checkmark$ & & $\checkmark$ & & $\checkmark$ & \\
\hline Göhler & $\checkmark$ & $\checkmark$ & $\checkmark$ & $\checkmark$ & $\checkmark$ & $\checkmark$ & $\checkmark$ & $\checkmark$ & $\checkmark$ & $\checkmark$ & & $\checkmark$ & \\
\hline Axiom.Des. & & $\checkmark$ & $\checkmark$ & & $\checkmark$ & $\checkmark$ & $\checkmark$ & & $\checkmark$ & $\checkmark$ & & & \\
\hline VMF & \multicolumn{8}{|c|}{ RD is a subset and not specified further } & & $\checkmark$ & & & \\
\hline
\end{tabular}

Table 2: Summary of existing RD frameworks 


\section{Proposing a Robust Design Process (RDP)}

As outlined earlier in this paper, although broadly acknowledged, the current uptake and application of RD in industry is rather unsatisfactory. One reason being the gap between academic research and the practical application in industry. Another reason is the fuzziness of the RD toolbox with no coherent RD process as identified in the previous section.

\subsection{Derivation of a RDP}

The assumption behind the proposal of the RDP is that a process is inherently built and structured by the activities and methods it comprises. Reversing the argumentation, the coherences of the methods and activities form the process.

The eight mechanisms of RDM give a semi-structured description of the Robust Design toolbox. However, from the design engineer's point of view, it is not always clear how the methods fit into the everyday activities in a development project. The engineer is shifting back and forth between synthesis and analysis on both conceptual and detailed design levels and therefore the Robust Design Process should support this way of working. The RDP should, furthermore, addresses the requirements as stated in the introduction: 1) housing of all RD methods, 2) provision of an application sequence and 3) linking the RD methods to the activities of the design engineers. Table 3 summarizes the results from the previous section and connects the methods to the design activities of the engineer.

\begin{tabular}{|l|l|l|l|}
\hline No & Mechanisms of RDM & Tools/Methods & $\begin{array}{l}\text { What the designer does (Design } \\
\text { Activities) }\end{array}$ \\
\hline I & Robust concept design & $\begin{array}{l}\text { Selection of the working principle } \\
\text { and the conceptual design solution }\end{array}$ & $\begin{array}{l}\text { 1. Conceptual Design } \\
\text { In this context, conceptual design is } \\
\text { understood as defining a new } \\
\text { solution to a design problem, as } \\
\text { opposed to scaling (see below). }\end{array}$ \\
\cline { 1 - 3 } II & $\begin{array}{l}\text { Reduction of } \\
\text { couplings between } \\
\text { functions }\end{array}$ & Axiomatic Design Axiom 1 & Separation/Integration of functions \\
\hline
\end{tabular}




\begin{tabular}{|c|c|c|c|}
\hline \multirow{5}{*}{ III } & \multirow{5}{*}{$\begin{array}{l}\text { Reduction of number } \\
\text { of influencing factors }\end{array}$} & Axiomatic Design Axiom 2 & \\
\hline & & Design Clarity & \\
\hline & & Kinematic Design & \\
\hline & & Locating Schemes & \\
\hline & & Tolerance Chains & \\
\hline IV & $\begin{array}{l}\text { Design with } \\
\text { robustness margins }\end{array}$ & $\begin{array}{l}\text { Safety factors wrt. structural and } \\
\text { process capability data }\end{array}$ & \\
\hline $\mathrm{V}$ & $\begin{array}{l}\text { Measuring of system } \\
\text { response }\end{array}$ & Design of Experiments (DOE) & $\begin{array}{l}\text { 2. Data collection (measuring) and } \\
\text { modelling of the system response }\end{array}$ \\
\hline \multirow{4}{*}{ VI } & \multirow{4}{*}{$\begin{array}{l}\text { Modelling of system } \\
\text { response }\end{array}$} & $\begin{array}{|lll|}\begin{array}{l}\text { Analytical } \\
\text { Modelling }\end{array} & \text { Transfer } & \text { Function } \\
\end{array}$ & \\
\hline & & Design Matrix & \\
\hline & & $\begin{array}{l}\text { Response Surface Methodology and } \\
\text { other data fitting methods }\end{array}$ & \\
\hline & & $\begin{array}{l}\begin{array}{l}\text { Variation Mode and } \\
\text { Analysis }\end{array} \\
\text { Effects } \\
\end{array}$ & \\
\hline \multirow{7}{*}{ VII } & \multirow{7}{*}{$\begin{array}{l}\text { Processing and } \\
\text { evaluation of system } \\
\text { response }\end{array}$} & Design Structure Matrix (DSM) & \multirow{7}{*}{$\begin{array}{l}\text { 3. Process and Evaluate } \\
\text { (Graphs, metrics, visualizations and } \\
\text { deciding on further actions) }\end{array}$} \\
\hline & & Error Transmission Formula & \\
\hline & & Ishikawa / Fishbone Diagram & \\
\hline & & Monte-Carlo-Analysis (MCA) & \\
\hline & & P-Diagram & \\
\hline & & Pareto Analysis & \\
\hline & & Sensitivities Analysis & \\
\hline \multirow[t]{2}{*}{ VIII } & \multirow{2}{*}{$\begin{array}{l}\text { Scaling (optimization) } \\
\text { of design parameters }\end{array}$} & $\begin{array}{l}\text { Optimization of transfer function or } \\
\text { S/N-Ratio }\end{array}$ & \multirow{2}{*}{$\begin{array}{l}\text { 4. Detailed design and scaling } \\
\text { (optimization) of parameters and } \\
\text { tolerances }\end{array}$} \\
\hline & & \begin{tabular}{|l|} 
Tolerance Management \\
\end{tabular} & \\
\hline
\end{tabular}

Table 3: RDM mechanisms and engineering activities

To derive a Robust Design process the underlying activities that are performed by the design engineers need to be understood (Figure 1 step 2). The analysis of the eight mechanisms revealed 4 governing activities. Firstly, there are mechanisms that address the actual design of the product: these are robust concept design, reduction of couplings and influencing factors and designing with margins. Other mechanisms aim at the assessment and description of the functional performance (measuring and modelling of system response). Further, the last two mechanisms address the processing of the results and the optimization which again are two very different activities. In summary, the Robust Design efforts can be grouped in 4 different design steps: 1) using relevant principles and guidelines for obtaining a robust conceptual design, 2) measuring and modelling the robustness of the design, 3) processing the results and either redesigning 
(back to 1) or 4) optimizing the design. Based on these coherences and design activities associated with the methods of RD presented in this paper, we propose a Robust Design Process (RDP) to describe the Robust Design efforts and its methods and tools in a comprehensive and structured manner to guide design and development engineers for the application of Robust Design. The nature of the presented activities suggests a certain order and sequence of application which is shown in Figure 2. The boxes illustrate the design activities, the arrows present the results of each phase that are passed on.

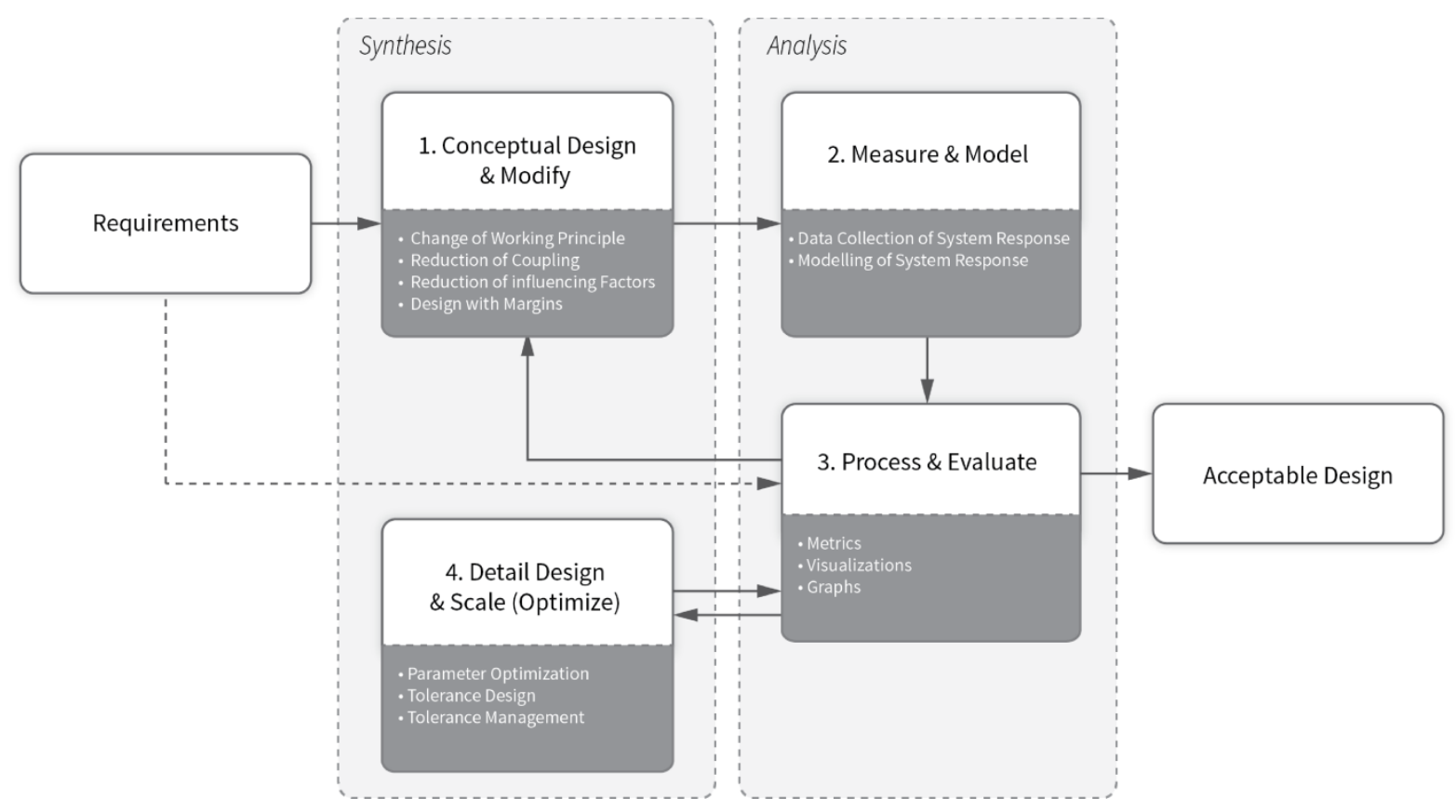

Figure 2: Robust Design Process

\subsection{The Phases of the RDP}

1. The conceptual design, i.e. the creation and further on the modification of the conceptual solution of the design, is the initial phase for the Robust Design Process and essential to establish a robust baseline. Activities in this phase change the inherent characteristics of the system response. It entails the choosing of an adequate working principle and the obeying of robustness 
principles and guidelines for each design iteration. Conceptual design decisions as described here do not only refer to the principle design solution on system level (as for example in the stage-gate-models) but entail design decisions down to, for example, the selection of a screw over a rivet to connect two pieces of sheet metal. The tools conveying this premise are associated with general engineering experience and lessons learnt from previous designs. This includes the selection of a robust concept, uncoupling the design, reduction of influencing factors and including design margins. Because the next phase - modelling and measuring the robustness of the design - is known to be complex and challenging, it can be an advantage to use sufficient efforts in the conceptual design phase, carefully pursuing a solution that is inherently robust.

2. The activities in the conceptual phase are logically followed by the application of tools to measure and model the response of the system for nominal values of the Design Parameters and Noise Factors and when subjected to ingoing variations. When seemingly simple designs are coupled or have ambiguous load paths, this step becomes incredibly difficult and time consuming. Some iteration between phase 1 and 2 may be required to produce a clear, unambiguous design suitable for this phase. The understanding of the system response and the mathematical description is necessary for the evaluation and processing of the data (phase 3) as well as for prediction and optimization of the design (phase 4).

\section{The third phase comprises the processing and evaluation of the} robustness data of the current design. The information can be conveyed in the form of metrics, graphs or illustrations. Checking the results against the requirements gives the basis to decide whether the design is acceptable as is or 
needs further improvements. This could entail a modification or redesign of the conceptual design solution or a scaling (optimization) of the existing solution. A reevaluation of the changed design is necessary to proceed. Note that the evaluation of the market as well as the quality loss associated with variation in functional performance and therefore the setting of functional requirements is not included in the RDP as delimited in the section 3. This information is assumed to be known and available.

4. In the case that the conceptual robustness has been judged to be satisfactory, the correlations gained in phase 2 can be utilized to optimize the robustness of the design. DPs are scaled to meet the target functional requirements but also to optimize the design for a minimized variance of the overall functional performance.

In a design process, these are recurring activities from the initial sketch to the final design. It is important to note that not all methods and tools associated with the four phases can be or are sensible to be applied in each iteration. Instead it shall be stressed that the proposed RDP gives structured guidance on when, which and how methods can be used and what their underlying mechanisms are.

\section{Discussion}

When proposing a new process, the usefulness, applicability and interaction with existing processes is of critical importance. In this section we discuss and reflect on some of the most important questions. However, this does not replace a rigorous validation.

How would the RDP be applied in a real product development situation? 
Development engineers of any kind face very specific tasks and deliverables every day. Realizing what phase of the RDP a given task lays in is of high importance to systematically address the robustness of the product. Are certain phases skipped? Have all options in the conceptual design phase been exhausted to achieve the highest possible level of inherent robustness? Can we go ahead with the measuring (experimentation, prototyping etc.) and modelling of the system or are there, for example, too many ambiguities increasing the complexity of the model, which are costly and time consuming? The same applies for the processing/evaluation and optimization phase. Are we sure that the current activity is the most efficient and effective one to achieve the most robust design in a given situation? What tools and methods are available for my specific task and deliverable?

Being able to place ones activity in the RDP and selecting an appropriate method, enables the engineer to systematically address robustness considerations in the most effective and efficient manner.

From the managerial perspective, the RDP offers the possibility to establish an organized toolbox including only methods and tools appropriate for the company or department. The selection can be done based on the typical engineering tasks in the context of the product, organization, expertise etc. A reduced toolbox with the knowledge about the mechanisms of the individual methods will increase the clarity and therefore the speed and effectiveness of the application.

How does the RDP relate to generic product development processes e.g. the stage/gate or V-models?

It is widely acknowledged that product development is an iterative rather than a linear process (Summers and Shah 2010). Iterative process models like the V-model or agile product development are well established in industry. In practice, certain functions in 
the product are either reused from previous products or are chosen to be frontloaded to give a proof-of-concept, which makes the development process highly non-linear. To support this, the RDP is defined in a way that it is decoupled from existing generic development models and it is the intent that the RDP is applicable at any stage of the development process. In agreement with that, work by Hasenkamp et al. (2007) shows that certain RD methods can be used in various phases of a generic PDP.

How should RDP be implemented in industry?

The way of applying RDM in practice varies very much - from non-existent but acknowledged to highly integrated. Also the reasons for application differ from company to company. Krogstie et al. (2014) assessed four companies that have successfully integrated RD. The approaches for integrating RD in their general product development processes differ from robustness metrics for milestones, common understanding in DfSS reviews to specific requests of RD activities by the management and integration into lean processes. The iterative $\mathrm{RD}$ process as proposed in this paper covers all these approaches. Studies and experiences have shown that "tool-pushing" from the management for specific RD tools was unsuccessful (Fazl Mashhadi, Alänge, and Roos 2012). The answers to "Why?" and "How?" to apply RDM are critical for the understanding of the practitioners, i.e. the engineers, and therefore the successful integration. The RDP is therefore thought as a framework for companies to establish their individual RD toolbox and practices. The companies' individual foci are reflected in the model. The assessment and quantification of robustness as well as the visualization and communication plays an essential role in the Robust Design work of these companies. 


\section{Conclusion}

The field of Robust Design (RD) includes a wide range of tools and methods. However, a clear process connecting these and supporting the application does not exist. It is still being reported that the integration of RD in industry is not widely spread and that tools and methods for RD are perceived to be too complex and unorganized with no actual guidance for application. This leads to great efforts for implementation including excessive training and tool pushing rather than a natural pull from the design engineers based on the benefits of using Robust Design.

In this study we analyzed 23 methods commonly associated with Robust Design and found eight underlying independent mechanisms of how these methods work. Based on those we propose a novel Robust Design Process (RDP) with 4 main phases covering the actual activities of the design engineer: 1) Conceptual design, 2) Measure and model, 3) Process and evaluate, 4) Optimize. The goal is to support the application by clarifying and structuring the use and application of RD methods. Keeping in mind that product development processes are very non-linear in real life as opposed to the descriptions in many academic publications, the nature of the RDP also supports an iterative approach, and is applicable in all design stages. We show that there is a logical sequence for the application and address the applicability to the design engineers. The comparison with RD efforts in the industrial context shows that an application of the proposed process is possible. The RDP is of interest for engineers, lead engineers and management to understand and manage the efforts made to increase, manage and control robustness. Also the training of Robust Design and the creation of company Robust Design Toolboxes can be built upon the proposed framework. The structured and systematic approach to Robust Design by means of a coherent process is needed to increase the uptake in industry. 


\subsection{Future work}

The aim of the Robust Design Process proposed in this article is to support the application of RD in industry and provide a better overview and understanding of the RD toolbox. However, the actual usefulness and usability of the process has only been reflected on briefly (Section 6). Validation studies are necessary on project and corporate level. Does the RDP improve the understanding and foster the efficient use of RD methods and tools in practice? To answer that question a study could be run to assess the selection and application of RD methods with and without support of the RDP. On corporate level the benefits of using the RDP could be studied for building a balanced RD toolbox or consolidate and organize an existing one. Another interesting study could be on the integration of quantifiable metrics to steer and measure the robustness of a product.

\section{Acknowledgements}

The authors would like to thank Novo Nordisk and the Valcon Robust Design Consultancy for their support for this research project.

\section{References}

Andersson, Peder. 1996. “A Process Approach to Robust Design in Early Engineering Design Phases."

Antony, Jiju. 2003. Design of Experiments for Engineers and Scientists. International Journal of Engineering.

Araujo, C. S., H. Benedetto-Neto, A. C. Campello, F. M. Segre, and I. C. Wright. 1996. "The Utilization of Product Development Methods: A Survey of UK Industry." Journal of Engineering Design. doi:10.1080/09544829608907940.

Bertini, Francesco. 2012. "A Path Toward the Aerodynamic Robust Design of Low Pressure Turbines." Journal of Turbomachinery 135 (March 2013): 021018. doi:10.1115/1.4007519.

Box, G. E. P., and K. B. Wilson. 1951. "On the Experimental Attainment of Optimum Conditions." Journal of the Royal Statistical Society 13 (1959): 1-45. doi:10.1007/978-1-4612-4380-9_23.

Chase, Kenneth W., and Alan R. Parkinson. 1991. "A Survey of Research in the 
Application of Tolerance Analysis to the Design of Mechanical Assemblies." Research in Engineering Design 3 (1): 23-37. doi:10.1007/BF01580066.

Chen, Wei, J. K. Allen, Kwok-Leung Tsui, and F. Mistree. 1996. "A Procedure for Robust Design: Minimizing Variations Caused by Noise Factors and Control Factors." Journal of Mechanical Design. doi:10.1115/1.2826915.

Creveling, Clyde M., Jeff Slutsky, and Dave Antis. 2002. Design for Six Sigma in Technology and Product Development. Englewood Cliffs, NJ: Prentice Hall.

Ebro, Martin, Thomas J Howard, and Janus Juul Rasmussen. 2012. "The Foundation for Robust Design: Enabling Robustness through Kinematic Design and Design Clarity." In Proceedings of International Design Conference, DESIGN, DS 70:817-26.

Eifler, Tobias, Martin Ebro, and Thomas J. Howard. 2013. "A Classification of the Industrial Relevance of Robust Design Methods." In International Conference on Engineering Design, 1-10.

Eifler, Tobias, Johannes Mathias, Roland Engelhardt, Hermann Kloberdanz, Andrea Bohn, and Herbert Birkhofer. 2011. "Evaluation of Solution Variants in Conceptual Design by Means of Adequate Sensitivity Indices." In ICED 11 - 18th International Conference on Engineering Design - Impacting Society Through Engineering Design, 9:314-23.

Fazl Mashhadi, Azadeh, Sverker Alänge, Göran Gustafsson, and Lars-Uno Roos. 2015. "The Volvo Robust Engineering System: How to Make Robust Design Work in an Industrial Context." Total Quality Management \& Business Excellence, no. May: 1-19. doi:10.1080/14783363.2015.1039938.

Fazl Mashhadi, Azadeh, Sverker Alänge, and Lars-Uno Roos. 2012. "Introducing Robust Design in Product Development: Learning from an Initiative at Volvo." Total Quality Management \& Business Excellence. doi:10.1080/14783363.2012.728847.

Forouzandeh Shahraki, Ameneh, and Rassoul Noorossana. 2014. "Reliability-Based Robust Design Optimization: A General Methodology Using Genetic Algorithm." Computers \& Industrial Engineering 74. Elsevier Ltd: 199-207. doi:10.1016/j.cie.2014.05.013.

Fujita, Kikuo, and Takahiro Matsuo. 2005. "Utilisation of Product Development Tools and Methods." In International Conference on Engineering Design ICED05, 1-14.

Geraci, Anne, Freny Katki, Louise McMonegal, Bennett Meyer, and Hugh Porteous. 1991. IEEE Standard Computer Dictionary. A Compilation of IEEE Standard Computer Glossaries. IEEE Std 610. doi:10.1109/IEEESTD.1991.106963.

Goh, T. N. 2002. "A Strategic Assessment of Six Sigma.” Quality and Reliability Engineering International 18 (October 2001): 403-10. doi:10.1002/qre.491.

Gremyr, Ida, Martin Arvidsson, and Per Johansson. 2003. "Robust Design Methodology: Status in the Swedish Manufacturing Industry." Quality and Reliability Engineering International 19 (4): 285-93. doi:10.1002/qre.584.

Gremyr, Ida, and Torben Hasenkamp. 2011. "Practices of Robust Design Methodology in Practice." The TQM Journal. doi:10.1108/17542731111097489.

Göhler, Simon Moritz, and Thomas J. Howard. 2014. "A Framework for the Application of Robust Design Methods and Tools." In 1st International 


\section{Symposium on Robust Design.}

Hasenkamp, Torben. 2010. "Engineering Design for Six Sigma-a Systematic Approach." Quality and Reliability Engineering International. doi:10.1002/qre.1090.

Hasenkamp, Torben, Tommy Adler, Anders Carlsson, and Martin Arvidsson. 2007. "Robust Design Methodology in a Generic Product Design Process." Total Quality Management \& Business Excellence 18 (4): 351-62. doi:10.1080/14783360701231294.

Hasenkamp, Torben, Martin Arvidsson, and Ida Gremyr. 2009. "A Review of Practices for Robust Design Methodology." Journal of Engineering Design 20 (6): 645-57. doi:10.1080/09544820802275557.

Hermansson, Tomas, Johan S Carlson, and Staffan Bjo. 2013. "Geometric Variation Simulation and Robust Design for Flexible Cables and Hoses." Journal of Engineering Manufacture 227 (5): 681-89. doi:10.1177/0954405413476627.

Howard, Thomas J., Martin Ebro, Tobias Eifler, Søren Petersen, Simon Moritz Göhler, Aryan Christiansen, and Andreas Rafn. 2014. "The Variation Management Framework (VMF) for Robust Design.” In 1st International Symposium on Robust Design, 1-9. doi:10.4122/dtu.

Hutcheson, Ryan S, and Daniel A Mcadams. 2012. "Sensitivity Measures for Use during Conceptual Design.” International Journal of Design Engineering 5 (1).

Kang, D. O., S. J. Heo, M. S. Kim, W. C. Choi, and I. H. Kim. 2012. "Robust Design Optimization of Suspension System by Using Target Cascading Method." International Journal of Automotive Technology 13 (1): 109-22. doi:10.1007/s12239-012-0010-y.

Krogstie, Lars, Martin Ebro, and Thomas J. Howard. 2014. "How to Implement and Apply Robust Design: Insights from Industrial Practice." Total Quality Management \& Business Excellence, no. August (July): 1-19. doi:10.1080/14783363.2014.934520.

Lijuan, Shen, Yang Jun, and Zhao Yu. 2011. “An Integration Design Optimization Framework of Robust Design, Axiomatic Design, and Reliability-Based Design." Quality and Reliability Engineering International 27 (February): 959-68. doi:10.1002/qre.1188.

Matthiassen, Benny. 1997. "Design for Robustness and Reliability: Improving the Quality Consciousness in Engineering Design.” Technical University of Denmark.

Mørup, Mikkel. 1993. "Design for Quality."

Pahkamaa, Andreas, Kristina Wärmefjord, Lennart Karlsson, Rikard Söderberg, and John Goldak. 2012. "Combining Variation Simulation With Welding Simulation for Prediction of Deformation and Variation of a Final Assembly." Journal of Computing and Information Science in Engineering 12 (June 2012): 021002. doi:10.1115/1.4005720.

Pahl, Gerhard, Wolfgang Beitz, Jörg Feldhusen, and Karl-Heinrich Grote. 2007. Engineering Design: A Systematic Approach. A NASA STI/Recon Technical Report. Springer Science \& Business Media. doi:10.1007/978-1-84628-319-2.

Saha, Amit, and Tapabrata Ray. 2011. "Practical Robust Design Optimization Using Evolutionary Algorithms." Journal of Mechanical Design 133 (October 2011): 
101012. doi:10.1115/1.4004807.

Schleich, Benjamin, Michael Walter, Sandro Wartzack, Nabil Anwer, and Luc Mathieu. 2012. "A Comprehensive Framework for Skin Model Simulation." In Proceedings of the ASME 2012 11th Biennial Conference on Engineering Systems Design and Analysis, 567-76.

Steenackers, G., R. Versluys, M. Runacres, and P. Guillaume. 2011. "Reliability-Based Design Optimization of Computation-Intensive Models Making Use of Response Surface Models." Quality and Reliability Engineering International 27 (December 2010): 555-68. doi:10.1002/qre.1166.

Suh, Nam P. 2001. Axiomatic Design: Advances and Applications. New York: Oxford University Press.

Summers, Joshua D., and Jami J. Shah. 2010. "Mechanical Engineering Design Complexity Metrics: Size, Coupling, and Solvability." Journal of Mechanical Design. doi:10.1115/1.4000759.

Söderberg, R., L. Lindkvist, and J. S. Carlson. 2006. "Managing Physical Dependencies through Location System Design." Journal of Engineering Design 17 (4): 325-46. doi:10.1080/09544820500275685.

Taguchi, Genichi, Subir Chowdhury, and Yuin Wu. 2005. Taguchi's Quality Engineering Handbook. Hoboken, NJ: John Wiley \& Sons.

Tang, Yuanfu, Jianqiao Chen, and Junhong Wei. 2012. "A Sequential Algorithm for Reliability-Based Robust Design Optimization Under Epistemic Uncertainty.” Journal of Mechanical Design 134 (January 2012): 014502. doi:10.1115/1.4005442.

Thornton, Anna C. 2004. Variation Risk Management: Focusing Quality Improvements in Product Development and Production. Hoboken, NJ: John Wiley \& Sons.

Thornton, Anna C, Stephen Donnelly, and Basak Ertan. 2000. "More than Just Robust Design: Why Product Development Organizations Still Contend with Variation and Its Impact on Quality." Research in Engineering Design. doi:10.1007/s001630050028.

Welch, William. J., Tat-Kwan Yu, Sung Mo Kang, and Jerome Sacks. 1990. "Computer Experiments for Quality Control by Parameter Design.” Journal of Quality Technology 22: 15-22.

Yadav, Om Prakash, Sunil S. Bhamare, and Ajay Rathore. 2010. "Reliability-Based Robust Design Optimization: A Multi-Objective Framework Using Hybrid Quality Loss Function." Quality and Reliability Engineering International 26 (June 2009): 27-41. doi:10.1002/qre.1027.

Yang, Changming, and Xiaoping Du. 2014. "Robust Design for Multivariate Quality Characteristics Using Extreme Value Distribution." Journal of Mechanical Design 136. doi:10.1115/1.4028016.

Yang, Guangbin. 2007. "Reliability Improvement Through Robust Design." In Life Cycle Reliability Engineering, 122-93. doi:10.1002/9780470117880.ch5. 